with different concentrations $(5,25,50,100 \mu \mathrm{g} / \mathrm{ml})$ and different exposure time $(50 \mu \mathrm{g} / \mathrm{ml} \mathrm{CRP} \mathrm{coincubated} \mathrm{for} 6,12,24$ and $48 \mathrm{~h})$. The protein expression of TLR4 was measured by flow cytometry and mRNA expression of TLR4 and MD-2 were tested by quantitative PCR. Measurements of TNF $\alpha$, IL-6 and MMP-9 in the supernatants of cultured monocytes were performed by ELISA.

Results CRP (5, 25, 50 and $100 \mu \mathrm{g} / \mathrm{ml})$ increased dose-dependently the expression of TLR4 protein $(32.22 \pm 2.80 \%, 49.94 \pm 5.58 \%$, $74.82 \pm 3.24 \%$ and $90.82 \pm 2.88 \% ; p<0.005$ vs control, respectively).

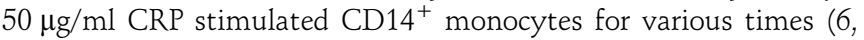
12,24 and $48 \mathrm{~h}$ ) and also increased time-dependently the expression of TLR4 protein $(29.80 \pm 2.70 \%, 47.44 \pm 4.41 \%, 81.71 \pm 2.92 \%$ and $50.57 \pm 3.34 \% ; \mathrm{p}<0.005$ vs control, respectively). CRP $(5,25,50$ and $100 \mu \mathrm{g} / \mathrm{ml}$ ) increased dose-dependently the expression of TLR4 mRNA $(159 \%, 211 \%, 320 \%$ and $390 \%$; $<<0.005$ vs control, respectively) and MD2 mRNA (146\%, 236\%, 311\% and 416\%; $p<0.005$ vs

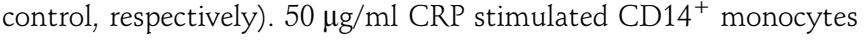
for various times $(6,12,24$ and $48 \mathrm{~h})$ and increased time-dependently the expression of TLR4 mRNA (162\%, 264\%, 354\% and 208\%; $\mathrm{p}<0.005$ vs control, respectively) and MD2 mRNA (147\%, 241\%, $311 \%$ and $190 \% ; p<0.005$ vs control, respectively). The release of TNF $\alpha$, IL- 6 and MMP-9 in the supernatants of monocytes treated with CRP increased dose-dependently. TLR4 inhibitor of high dose $(30 \mu \mathrm{g} / \mathrm{ml})$ could block the release of TNF $\alpha$, IL-6 and MMP-9 mediated by TLR4 and MD2 upregulated by CRP completely.

Conclusion CRP can active the signal transduction of TLR4 on $\mathrm{CD} 14^{+}$monocyte, and induced the production of TNF $\alpha$, IL- 6 and MMP-9. Our finding illustrates that CRP, as pathogen associated molecular (PAMP), may induce innate immune response in vitro by monocyte Toll-like receptor signalling.

\section{e0110 THE EFFECTS OF ATORVASTATIN ON C-REACTIVE PROTEIN INDUCED TOLL-LIKE RECEPTOR 4 EXPRESSION ON CD14+ MONOCYTE}

doi:10.1136/hrt.2010.208967.110

Jinlai Liu, Long Peng, Yanting Luo. Department of Cardiology, The Third Affiliated Hospital, Sun Yat-sen University, Guangzhou, China

Objective To observe the effects of atorvastatin on C-reactive protein (CRP) induced Toll-like receptor 4 expression on $\mathrm{CD} 14^{+}$ monocyte in human, and anti-inflammatory effect of atorvastatin. Methods $\mathrm{CD}_{14}{ }^{+}$monocytes were isolated from blood in healthy volunteers by the Ficoll density gradient and stimulated by CRP with different concentrations $(5,25,50,100 \mu \mathrm{g} / \mathrm{ml})$ and different exposure time $(50 \mu \mathrm{g} / \mathrm{ml} \mathrm{CRP} \mathrm{coincubated} \mathrm{for} 6,12,24$ and $48 \mathrm{~h}$ ). The protein expression of TLR4 was measured by flow cytometry and mRNA expression of TLR4 and MD-2 were tested by quantitative PCR. Measurements of TNF $\alpha$, IL-6 and MMP-9 in the supernatants of cultured monocytes were performed by ELISA.

Results CRP (5, 25, 50 and $100 \mu \mathrm{g} / \mathrm{ml})$ increased dose-dependently the expression of TLR4 protein $(32.22 \pm 2.80 \%, 49.94 \pm 5.58 \%$, $74.82 \pm 3.24 \%$ and $90.82 \pm 2.88 \% ; p<0.005$ vs control, respectively). CRP $50 \mu \mathrm{g} / \mathrm{ml}$ stimulated CD14 ${ }^{+}$monocytes for various times (6, 12,24 and $48 \mathrm{~h}$ ) and also increased time-dependently the expression of TLR4 protein $(29.80 \pm 2.70 \%, 47.44 \pm 4.41 \%, 81.71 \pm 2.92 \%$ and $50.57 \pm 3.34 \% ; \mathrm{p}<0.005$ vs control, respectively). Atorvastatin (1.0, $2.5,5.0,7.5$ and $10 \mu \mathrm{mol} / \mathrm{l})$ inhibited dose-dependently the expression of TLR 4 protein induced by CRP $50 \mu \mathrm{g} / \mathrm{ml}$ for $24 \mathrm{~h}[68.17 \%$, $52.43 \%, 27.72 \%, 17.46 \%$ and $9.99 \%$; $<<0.005$ vs control $(80.39 \%$ ), respectively], and restrained dose-dependently the expression of TLR4 mRNA ( $p<0.005$ vs control, respectively) and MD2 mRNA $(p<0.005$ vs control, respectively). The release of TNF $\alpha$, IL-6 and MMP-9 in the supernatants of monocytes treated with CRP $50 \mu \mathrm{g} /$ $\mathrm{ml}$ was inhibited dose-dependently by atorvastatin. Atorvastatin $10 \mu \mathrm{mol} / 1$ inhibited mostly the release of TNF $\alpha$, IL- 6 and MMP-9 in the supernatants of monocytes treated with CRP $50 \mu \mathrm{g} / \mathrm{ml}(24 \%$, $22.6 \%$ and $15.6 \%, \mathrm{p}<0.005$ vs baseline, respectively).

Conclusion CRP can increase dose-dependently and time-dependently the expression of TLR4 on $\mathrm{CD}_{14}{ }^{+}$monocyte in human, and the production of TNF $\alpha$, IL- 6 and MMP-9 in CD14 ${ }^{+}$monocyte. Atorvastatin can inhibit dose-dependently the expression of TLR4 mRNA and protein induced by CRP and the release of TNF $\alpha$, IL-6 and MMP-9 in CD14 ${ }^{+}$monocytes in human. Atorvastatin has antiinflammatory effects and may restrain innate immune response in vitro by inhibition of monocyte Toll-like receptor signalling.

\section{e0111 ASSOCIATION BETWEEN MYELOPEROXIDASE -463 G/A GENE POLYMORPHISM AND ITS PLASMA LEVELS WITH RISK OF CORONARY ARTERY DISEASE IN CHINESE POPULATION}

doi:10.1136/hrt.2010.208967.111

Han Lili, Shen Xiaoli, Lin Saimei, Pan Leng, Liu Xiaoging, Pu Xiaodong, Deng Yulian. Affiliated Fujian Provincial Hospital, Fujian Medical University/Fujian Provincial Key Laboratory of Cardiovascular Disease

Objective The aim of this study was to investigate whether myeloperoxidase gene polymorphism and its plasma levels were associated with risk of coronary artery disease (CAD) in Chinese population.

Methods A case-control study was conducted in Fujian provincial hosipital, 157 patients with established $\mathrm{CAD}$ (cases) and 78 individuals without angiographically significant $\mathrm{CAD}$ (controls) were enrolled. Blood samples were collected to identify the MPO polymorphism and its plasma levels.

Results Genotypes were determined in all individuals. The frequencies of three genotypes were significantly different in both group $(p<0.05)$. Plasma MPO levels were significantly greater in patients with CAD than in controls $(332.05 \pm 167.56 \mathrm{pg} / \mathrm{ml}$ vs $277.81 \pm 142.68 \mathrm{pg} / \mathrm{ml}, \mathrm{p}<0.05)$. In the case group, $7(4.5 \%)$ were homozygous for AA, 101(64.3\%) for GG and 49(31.2\%) were heterozygous. Mean MPO plasma levels were $200.10 \pm 31.47 \mathrm{pg} / \mathrm{ml}$ for AA, 297.43 $\pm 125.28 \mathrm{pg} / \mathrm{ml}$ for $\mathrm{AG}$ and $367.66 \pm 177.14 \mathrm{pg} / \mathrm{ml}$ for GG genotypes. In the case group, the MPO levels with GG were significantly higher than that in individuals with $\mathrm{GA}(\mathrm{p}<0.05)$ and $\mathrm{AA}(\mathrm{p}<0.05)$, but with no difference between GA and AA genotype ( $p>0.05)$. Plasma MPO levels correlated with its genotype.

Conclusion We found association between MPO polymerase and its plasma levels with CAD risk in Chinese population. These findings provide new sights for atherosclerosis diagnosis and risk assessment.

Acknowledgements This work was supported by a grant from the Nature Science Foundation of Fujian Province (2006J0326, X0650036).

\section{e0112 STUDY OF MYELOPEROXIDASE LEVEL AND CD11B/CD18 EXPRESSIONS ON LEUKOCYTES IN PATIENTS WITH CORONARY HEART DISEASE}

doi:10.1136/hrt.2010.208967.112

Han Lili, Shen Xiaoli, Lin Saimei, Pan Leng, Liu Xiaoqing, Pu Xiaodong, Deng Yulian. Affiliated Fujian Provincial Hospital, Fujian Medical University/Fujian Provincial Key Laboratory of Cardiovascular Disease

Objective Myeloperoxidase (MPO) and CD11b/CD18, markers of leukocyte activation, are involved in the pathogenesis of atherosclerosis. The aim of the study was to investigate the plasma MPO level and CD11b/CD18 expressions on leukocytes in patients with coronary heart disease (CHD).

Methods This case-control study included 157 patients with angiographically proven CHD (cases). Controls included 78 subjects with normal coronary angiograms. MPO was measured using an 